\title{
Razão-Poesia: comunicação, poesia e pensamento
}

\author{
Florence Dravet', Gustavo de Castro ${ }^{2}$
}

\begin{abstract}
Resumo: Na transmissão da informação, na sedução para venda, na persuasão ideológica e no entretenimento, os discursos midiáticos valem-se, entre outros elementos comunicativos, de recursos poéticos. Mas não é somente aí que se verifica a interação entre Comunicação e Poesia, esta incide também na construção dos saberes. Nesta perspectiva, a Razão-Poesia se apresenta como um caminho de teorização para a Comunicação, desde que se conceba três possibilidades de interação no pensamento: a possibilidade do diálogo entre a razâo - no sentido do logos heraclitiano - c a pocsia formal; a possibilidade da dialogia entres os saberes de uma poesia que não se restringe ao dominio do demens; c, por fim, a possibilidade de uma teorização que não se recuse a conduzir suas buscas seguindo os caminhos apontados por noçoes poéticas, inauguradas na poesia, tal como o Principio com, o Aberto c a Transparência.
\end{abstract}

Palavras-chaves: Comunicação, Poesia, Pensamento, Razão, Sensibilidade

Abstract: In the transmission of information, in the seduction to sale, in the ideological persuasion and entertainment, the discourses in the media cmploy: - among other communication clements - poetic resources. However, it is not the only case where one can verify the interaction between Communication and Poetry, this interaction is also present in the building of knowledge. From this perspective, Reason-Poetry presents itsclf as a path of theorization for Communication, provided that threc possibilities of interaction in thinking are conceived: the possibility of dialogue betwecn reason - in the Heraclitan I oggas sense - and formal poctry; the possibility of dilogy between the knowleges of a poetry that does not restrict itsclf to the domain of the demens; and, finally; the possibility of a theorization that does not refuse to conduct its quests

1 Florence Dravet é doutora em Ciencias da Linguagem pela Universidade de Paris li1 - professora dos Cursos de Comunicaçào e do Programa de pris-graduação em Comunicaçào

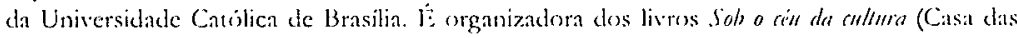
Musas, 2004) c Or satheries de comminacion (Casa das Musas, 2007).

2 Gustavo de Casto é doutor em Antropologia pela PUC/SP e professer de Comuni.

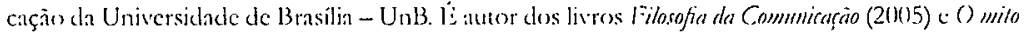

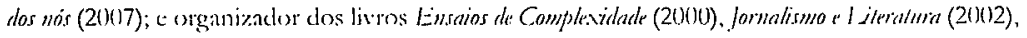

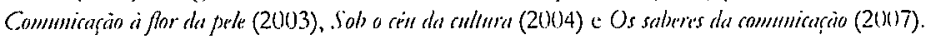


following the paths indicated by poetic notions, inaugurated in poetry, such as the Com Principle, the Open and the Transparency.

Keywords: Communication, Poetry, Thinking, Reason, Sensibility

A história do pensamento comunicacional carece de um questionamento à poesia. Esse questionamento não exclui a poesia do universo cultural da informação, muito pelo contrário. A história da publicidade brasileira registra o quanto esta deve àquela; o cinema não seria cinema e a crônica jornalística não seria a mesma sem os auspícios do sussurro poético. O desenvolvimento tecnológico dos meios de comunicação pode não ter favorecido à primeira vista - em quase cem anos de estudos acadêmicos da cultura de massa - o poético, que sempre esteve, ao que parece, a reboque dos interesses comerciais. No entanto, a prática (acadêmica, midiática e técnico-comunicacional) tem mostrado que a expansão da criação e a produção de imagens pela indústria comercial defrontaram-se a cada dia com o inesperado, o desconcerto, a metáfora e a complexidade da poesia. Desde que a produção audiovisual e jornalística acertaram o casamento entre o real e a imaginação, instalou-se o risco dos diálogos subseqüentes.

Em um desses diálogos, entre as cifras astronômicas do mercado de cultura industrial e a fantasia - sendo esta a alma gêmea da imaginação e, por isso mesmo, descompromissada com qualquer limite de realização - ocorre o que podemos chamar de insurreição poética. Ao vender fantasia, imaginação e sonho (e, às vezes, até utopia), os massmedia e a indústria de cultura acabam por fornecer historicamente (talvez sem querer e sub-repticiamente), insurreições poéticas de toda ordem. Através das conexões poéticas presentes nas obras artísticas historicamente produzidas, a poesia tornou-se viral.

Esse efeito viral consiste na contaminação lenta, gradativa e processual de todos os produtós da cultura industrial pelo vírus $\mathrm{da}$ poesia. Esse contágio ganha força à medida que seus recursos vão sendo paulatinamente utilizados para vender ou para emocionar o público. É verdade que nem sempre esse contágio é favorável. Em muitos casos, torna a obra apelativa, plena de clichês poéticos. Noutros, a obra ganha em cor e vibração. A analogia, a metáfora e o canto (notadamente o popular), as estratégias ritmicas, a capacidade imagética da poesia, tudo isso, sabemos, vem sendo utilizado anos a fio 
pelos agentes da publicidade, do cinema e, mais modestamente, do jornalismo. Mais recentemente, o Jornalismo Literário reapareceu como avant-guarde narrativa, o que podemos inferir também como um padrào de interação entre a comunicação e a poesia.

\section{Primeira aproximação à razão-poesia: as possibilidades de diálogo}

A velha questão platônica apresentada nos Livros $V \mathrm{e} X$, de A República, sobre a necessidade e a verdade da poesia sempre aparecerá como um problema a ser retomado quando o assunto é o de sua utilidade conceitual e científica. É fato que o cogitar sobre a poesia insemina-se na história do pensamento a partir de um caminho crítico adotado por Platão, muito embora nào possamos afirmar que um sentido semelhante não estivesse também presente nos pré-socráticos. Pensar a poesia é pensar a vida. Com os pré-socráticos não deve ter sido diferente. Todavia, os pré-socráticos estavam mais para uma razão com a poesia, uma razão sensivel, inserida no mágico e vinculada a ele, do que para uma razão sobre a poesia.

Essa diferença na proposição determina una forma especifica de lidar com o conhecimento. E não apenas o conhecimento poético. O sobre a e nào o com a dá um caminho distinto ao pensamento, assim como daria o wa e o pela; cada pequeno detalhe na linguagem comunica um novo caminho. Ou quase. $O$ quase também poderia ser pensado como outro elo de ligação, assim: razão ${ }^{3}$ quase poesia ou poesia quase razão. Abramos outros leques: o quando, o como, o qué.. Em cada pequeno movimento, novos mundos se revelam em caminhos surpreendentes para o pensamento. Como se fossem novas portas ou novas paisagens. Saber perguntar é mais importante do que achar as respostas. A resposta é regozijo passageiro, temporário, mas as perguntas não. Elas mantèm o método vivo, garantem o processo e o ser-que-busca.

3 Precisamos teiterar agui que adotamos como ponto de partida para acuile que chamamos "arão" a noçño de Geurg Philipp Friedrich son Hardenberg, mais conhecido como Novalis (1772-1801), que tentou unir, seguindo a tadiçáo do pensameno clissico, o logos de Hericlitu eo de $A$ ristóteles, recriando (c ampliando) o conccito. () yue ele chamen de lagologit covolve tanto a razà como racionalidade (estruturada pela dinamica do discurso) quanto a azăo encuanto logos (ligada ao pensamento, a linguagem, mais abrangente do que o proprio scntido de razão abarca). 
Em cada pequeno detalhe novos entes, outros valores, novas possibilidades. E se insistirmos na pergunta: por que não uma 'razão quase poesia"? Talvez a intuição de Nietzsche (analisando a música) e de Heidegger (analisando poemas) tenha sido a de uma razão vir-a-ser poesia sem deixar de ser razão, sem deixar de ser poesia.

Não falamos assim como se uma e outra não tivessem lá seus nichos de alcova, assim como suas diferenças. Hölderlin não acreditava que uma filosofia pudesse nascer em um terreno que não fosse arado pela poesia. Alguns pensamentos investem na poesia da mesma forma que algumas poesias investem na razão, no pensamento, na filosofia.

Os quadros dialogantes e as possibilidades de auto-eco-alimentação dos saberes assim como o investimento na reforma do pensamento nem sempre são bem vindos. De tempos em tempos o pensamento necessita girar, soltar suas amarras e lançar-se em mar aberto. Nada se mantém se o ser-que-busca, o ser-aberto, não estiver em atividade. Os racionalistas empedernidos ficariam espantados com esse possível vir-a-ser da razão: a poesia. Pois se não sabemos mesmo para onde ela caminha, que podemos afirmar com certeza? Tais racionalistas entenderiam se fosse esse o subverter que a razão preparou para si mesma? Enquanto uns vêem na razão um futuro ligado à tecnociência, outros apontam seus enganos passados. Estamos em um mundo bigh tec, cyborg, com cérebros artificiais e frankensteins baby sitters e estamos em submundos pulsantes, imaginais, semelhantes aos da realidade fantástica, de sensibilidades novas, com abertura não mais a uma única realidade, mas a uma multi-realidade existencial e temporal.

A razão continua tecendo fios ignotos em dimensões abertas, ainda incompreensíveis. Costuma sustentar bandeiras em labirintos abstratos, por vezes caminha como um vidente em noite escura. Foi isso o que intuiu Juarroz. Conhecedor da sua noite, disse certa vez: 'o papel do poeta é bem humilde, porque consiste em estar a serviço da sua noite'(apud BOIDO, 1980, 38). Acontece que as bases da poesia residem num fundamento polissêmico e multiunívoco. Não valeria a mesma base para a razão? A poesia é, por isso, um perigo à razão, adverte-nos, entre outras coisas, Platão. O que ele esqueceu de avisar é que a poesia seria também uma possibilidade. Uma possibilidade ao trabalho da razão.

Não foi Heráclito quem disse pela primeira vez que o pensa- 
mento sobrevive no limite de sua própria destruição? E quem disse que essa experiência do pensamento-poesia nào poderia ser uma possibjlidade? A medicina de Empédocles e o logos de Heráclito tiveram os seus resultados abstratos validados. Se não tivessem, que estariamos fazendo nós aqui, agora: delirando? Talvez.

O problema da razão é o mesmo da poesia: ninguém confia mais tanto assim nos seus produtores nem nos seus resultados. $O$ investimento maciço na razão provocou efeitos destruidores por todos os lados. O efeito da ditadura da forma sobre a poesia também. $\Lambda$ razão, sentada no divã, confessou ter feito coisas absurdas a partir da auto-confiança em si mesma. Confessa à filosofia e à ciência (ambas também no divà dos saberes) que nào consegue livrar-se de seu pretenso estado-maior, quiçá superior, porque não consegue deisar de ser, no fundo, aberta, espiritual. Coisa que a ciência não aceita muito bem. Sua materialidade excessiva trouxe-lhe também a depressão, seguida pelo lexotan.

Mas isso não significa que a razão encontrou Jesus. Muito pelo contrário. Foi o seu lado dements quem lhe mostrou descaminhos. Esse lado demens é representado na Antropologia Fundamental de Edgar Morin pelas forças simbólicas, os elementos do enigma, o lado obscuro da arte, a perspectiva lúdica, imaginal, criativa, de sonho presentes no homem. A partir desse encontro, dirá Morin, do sapiens sapiens com o sapiens demens, e no entendimento de que a razào possui e produ\%, nela, o engano, é que a razão pode descer dois dedos de seu patamar de soberba. A razão começa a despertar do seu sonho egoísta. Ainda bem lentamente, à medida que se abre às conexões e possibilidades.

\section{Segunda aproximação à razão-poesia: a dialogia poesia-saberes}

Poucas são as referencias, dentro do pensamento comunicacional ou dentro das Teorias da Comunicação, que exploram notadamente a poesia ${ }^{4}$. Não podemos dizer que as Teorias da Comunicação

$4 \quad \lambda$ comunicaçio sempre foj pensada ou em seu aspeco histórico on ligandorat a outros compos do saber. $\lambda$ s linhas que mais se aproximam desu proposta foram o cullurul studies por ter incluido a arte e a literatua na comunicaçios - ainda assim, esta foi submedicta a uma visão marxista sucio-antropológica e nào foi pensada suficientenuente como participaçio da ane no pensamento comunicacional - e, no Brasil, a folksommiracio com os cstudos da literutura de cordel. Verificamos cm nosso estudo tambem a bibliogratia clássica aplicada nas escolas de comunicaçào. Nesse sentido, as referéncins sào ainda cscassists. 
não se interessam pelas questões poéticas ou estéticas. Mas queremos ir além. É a poesia não só enquanto meio de expressão mas também enquanto pensamento do profundo ${ }^{5}$ que nos interessa diretamente aqui. Ao percorrer as diversas teorias conexas ao campo da comunicação em busca do espaço dedicado à poesia, encontramos na Teoria da Complexidade, de Edgar Morin, um lugar para essa dimensão da linguagem e da condição humana, ao lado da prosa. Morin chama a atenção para a importância de se reintegrar o encantamento e a poesia nas sociedades contemporâneas ocidentais, onde rupturas sucessivas no pensamento provocaram, segundo ele, uma disjunção entre o estado poético e o prosaico e uma desvalorização do primeiro em prol do segundo.

Houve duas rupturas. A primeira ocorreu a partir da Renascença, quando se desenvolveu uma poesia cada vez mais profana, ocorreu, igualmente, a partir do século XVII, uma outra dissociação entre uma cultura dita científica e técnica e uma cultura humanista, literária, incluindo a poesia. Foi a partir destas duas dissociações que a poesia autonomizou-se e tornou-se estritamente poesia. Separou-se da ciência, da técnica e, evidentemente, separou-se da prosa. (MORIN, 2002, 37)

Poesia, porém, não é apenas a dimensão simbólica, mítica, mágica e imaginária, o universo do devaneio, do sonho e da loucura distinto do universo lógico-técnico-racional. Poesia é também pensamento, um pensamento-imagem que, segundo Juarroz, foi cindido em um dado momento da história em dois universos distintos.

Há um momento bastante crucial na história do espírito humano em que se separam o que poderíamos denominar o conteúdo do pensamento e o conteúdo do que hoje chamamos imagem. Extirpar o pensamento da criação poética a empobrece sem remédio, pois no homem o pensamento é inşubstituível. A poesia além disso, não é simples razão ou simples sentimento, e é necessário re-

5 Noção utilizada por Roberto Juarroz para explicar o princípio estético do poeta Antônio Porchia (1885-1968). Esta "escuta do profundo", das essências, do que realmente importa, é uma característica desta corrente poética fundada em Buenos Aires no início do século XX com Porchia. Dela surgem outros poetas como Laura Cerrato, Roger Munier, Michel Camus e o próprio Roberto Juarroz. 
cuperar a perda de unidade entre pensamento e imagem. Na poesia há imagem, mas também o que poderíamos designar, paradoxalmente, como imagem do pensar ou imagem de pensamento. (...) Para mim, o pensar é juntar o que alguma vez se dividiu, o que não somos capazes de fazer a toda hora do dia. Juntar o que alguma vez se fracionou absurdamente para explicar ou para raciocinar: aqui a ciência, a filosofia e ali o que é arte, poesia. (JUARROZ, 1980, 39)

Em grego antigo, poesis é "fazer", "elaborar", "construir", aquilo que possibilita a criação ou a forma de linguagem que possibilita o novo e, a partir desse novo, permite que sejam tecidas as infinitas relações entre os vários níveis da realidade e da existência poeticamente tornada manifesta. Na comunicação como atividade perene do homem, a manifestação poética do ser convive intrínseca e permanentemente com a manifestação lógico-técnico-racional desse mesmo ser. Por que então não atribuir à poesia o seu lugar dentro do pensamento sobre a comunicação? $\mathrm{O}$ que impede que, após a longa história das diversas rupturas e do profundo distanciamento entre 0 modo do conhecimento lógico-racional-científico e o modo poético da apreensão da realidade, injciemos agora o caminho de volta que religará os saberes desconexos da prosa e da poesia?

Acaso, todo ato de comunicação não implica ao mesmo tempo o duplo movimento do pensar e do sentir? Quando pensamos, também não sentimos? E quando falamos, não estamos também imprimindo sentimento à nossa fala? Pensar uma coisa não é também senti-la? Não há ruptura na vida entre a atividade de pensar e de sentir, as duas coisas acontecem de uma só vez. Por isso, para pensar a comunicação, propomos pensar ao mesmo tempo os mecanismos conhecidos e explicados pela ciência e pensar o que não se explica e que somente o pensamento da poesia pode tornar cognoscivel. Mas, afinal, para que serve a poesia? A dialogia poesia-conhecimento é de interesse para as ciências humanas porque a primeira serve como campo de investigação e ampliação do próprio conhecimento científico. Obedecidos o rigor e a pertinência, a poesia pode ser um campo de investigação em diversos niveis:

a) na politica, como expressão de resistência. A este respeito, Alfredo Bosi (2000) escreveu um capitulo paradigmático na história da literatura brasileira no seu Ser e Tempo da Poesia, ao tratar da poesia 
como ação politizante, não só uma resistência aos regimes totalitários, mas também à barbárie, à desordem, ao desencanto e ao caos cotidiano.

b) na memória, como resgate e apreensão histórica. A poesia luta contra o esquecimento, favorece a pesquisa das mentalidades e das representações históricas, subsidia o respeito às tradições.

c) no conbecimento, como saber que franqueia imagens e idéias. Quando a idéia é associada a uma imagem, ela permanece infinitamente ativa e inexaurivel. A poesia é uma doadora de sentido que coincide com a abertura do homem ao mundo e do homem a si mesmo. Nesse sentido, participa do universo do conhecimento humano - o universo de Sopbia - que busca com-preender (partilhar conjuntamente o entendimento) dos sentidos múltiplos da natureza e do fazer (poesis) humano.

d) na antropossociologia. Ao 'brincar' com o sentido de realidade, ela consegue desfazer os significados e 'refazer' o homem, situando-o noutro patamar. A poesia questiona o homem e a sociedade ante seus afetos, escolhas, racionalizações'e estilos de vida. Há muito que a poesia moderna não consegue integrar-se, feliz, nos discursos correntes da sociedade. Compelida à estranheza e ao silêncio, ela penetra cada vez mais os rincões das buscas humanas essenciais.

e) na arte e na linguagem: o caráter da palavra poética não se associa apenas ao seu aspecto icônico ou metafórico, mas também à mediação imagética e às diversas mediações discursivas: o tempo, o modo, a pessoa, o aspecto, faces todas que a predicação verbal e imagética configura.

f) na mistica: "a contemplação e a admiração da natureza com os sentidos mas também com o coração e o pensamento" é a base da racionalidade poética na mística. A mística não descarta nada porque tudo pode ser via de acesso ao conhecimento mágico e sublime. Todos os elementos juntos oferecem aberturas que servem para dar sentido à vida, quando estão expressas em palavras que, no entrecruzamento de sensações diversas, resultam em efeitos numinosos, jogando luz sobre aquele que comunga poeticamente a vida.

6 Florence Dravet desenvolve, desde 2004, em sucessivos artigos (Cf. "Palavra inconsideradas na lagoa do conhecimento", IN: CASTRO, Gustavo. GALENO, Alex. Jornalismo e Literatura - a sedtufáa da palavra. São Paulo: Escrituras, 2002. e "Em busca da verticalidade da palavra". IN:CASTRO, Gustavo de. DRAVET, Florence. Sob o cén da cultura. Brasilia: Thesaurus/Casa das Musas,2004.) a palavra como' um problema e uma abertura, um enigma $\mathrm{e}$ uima revelação, elemento de conhecimento e de engano. $\Lambda$ s faces misticas e encantadas da palavra ainda não foram suficientemente pesquisadas pela ciência. 


\section{Terceira aproximação à razão-poesia: as noções poéticas}

Para expor a idéia de pensamento poético, precisamos de uma linguagem que se coloque à disposiçào da poesia, precisamos de conceitos e idéias abertas à poesia, por isso falaremos antes, aqui, em noções poéticas. Para almejar o poético o pensamento precisa estar disponivel e não pré-ocupado com uma linguagem anteriormente definida, usada e representada. O pensamento poético distingue-se do pensamento científico não só no fato de buscar noções poéticas, mas também na ordem lógica de sua construçào.

Pensar poeticamente é deixar a poesia conduzir o pensamento, ou seja, efetuar uma inversão no movimento de construção lógica do raciocínio, permitindo que a indefinição, a ambigüidade ou o paradoxo permaneçam por mais tempo e abram os campos da cognição através do sensivel. $\Lambda$ noçào poética de Serenidade, desenvolvida por Heidegger em livro homônimo é, nesse sentido, ao mesmo tempo, um método, um caminho para o pensamento e uma proposição moral. A noção poética permite o aguardar da criação (no sentido da palavra) dentro da atividade de pensar.

É importante salientar que, aqui, poesia não se reduz a nenhuma forma definida, podendo também estar presente na prosa e, ainda, na conversação ou na prática do viver cotidiano. Assim também a concebe Octavio Paz, quando distingue o poema, a poesia e 0 poético:

Um soneto não é um poema, mas uma forma literária, exceto quando esse mecanismo retórico - cstrofes, metros e rimas - foram tocados pela poesia. Há máquinas de rimar mas não de poetizar. Por outro lado, há poesia sem poema; paisagens, pessoas c fatos soam poéticos: são poesia sem ser poema. Pois bem, quando a poesia se dá como uma condensação do acaso ou é uma cristalização de poderes c circunstâncias alheios à vontade criadora do poeta, enfrentamos o poético. (PAZ, 2003, 14)

Se sua manifestação ideal se dá na língua, porque é nas palavras que ela encontra a conjunção necessária entre a significaçào e o canto (ritmo, harmonia, sonoridade, silèncio), ela também está presente em toda forma artística, onde constitui a sua essência fundamental. $O$ 
que importa na poesia é que ela é o lugar sagrado da língua, o lugar do fundamento misterioso das coisas, aquele capaz de dar voz à linguagem, sendo que ela é a própria linguagem indo em direção à verdade. Muito mais do que forma e conteúdo, poesia é tida aqui como busca pela revelação do Ser. Vista nesta perspectiva, ela é também a essência que fundamenta qualquer tipo de arte.

Entendo que a poesia é algo assim como o humus, o substrato de toda forma de criação. Se a arte é criação, a arte tem um fundamento ou uma essência poética no fundo, qualquer que seja sua modalidade, seu gênero ou sua forma. JUARROZ, 1980, 29)

Segundo Heidegger (1998), somente a poesia é criadora de verdade na medida em que somenite ela é capaz de criar na linguagem, ultrapassando os limites do conhecido, do representado, ou de efetuar uma "clareira" no Aberto. O Aberto': aquilo que não restringe, não impede, não tem limite; a grande totalidade de tudo o que não está restringido. A noção de' Aberto é àmbígua porque tanto significa 'a totalidade dos nexos ilimitados da cónexão pura', como também a abertura 'no sentido da ilimitação em que tudo vigora'. O Aberto é também o círculo mais vasto, aquilo que circunscreve tudo o que é; a circunscrição que circun-une todo ente. Ao efetuar uma clareira no Aberto, o poeta traz a verdade que se encontrava oculta.

Isso significa que não é só a ciência ou a filosofia que são produtoras de verdade, também o é a poesia. $\operatorname{Em} A$ origem da obra de arte $(1998,64)$, Heidegger afirma que a ciência é o 'desenvolvimento de um âmbito de verdade já abertọ', que ela só desenvolve 'aquilo que se prognostica como correto, quer possível, quer necessário' e que 'se e na medida em que uma ciência vai para além do correto em direção a uma verdade' passa a ser filosofia. A poesia é então aquela capaz de efetuar a abertura necessária à inovação no pensamento Por isso, é ela que permite mostrar aos homens uma verdade contida e revelada na palavra, através do exercício do pensamento. O pensadór a oferece então à ciência para ser estudada em todos os seus desdobramentos. Poesia é pensamento e este devé confrontar-se poeticamente à poesia e a seus três poderes: poetizar, pir $\mathrm{p}_{t 3}$ ensar, dizer.

7 Aberto: a noção aparece na poésia de Hölderlin e é retomada e ampliada por Rilke, tanto na sua poesia como $\mathrm{cm}$ seus escritos sobre poesia. Heidegger, em seguida, desenvolve a idéia de Aberto no texto "Para quê poetas". In: Caminhos de foresta. Lisboa: Fundação Calouste Gulbenkian, 1998 (ed. or. 1959). 
A poesia tem algo a dizer e o diz com palavras que recebem a beleza do pensamento; esta beleza se afirma na poesia porque ela é a única maneira de recorrer às formas não desgastadas e vulgarizadas da língua. Nesta perspectiva, o poeta é o dižente. Ele não é, de forma alguma, um mero instrumento passivo que cede passagem a palavras vindas de algum lugar enignático. Ele é o ator principal na construção do elo entre a região enigmática onde se origina a linguagem e a própria fala no dito da poesia, na medida em que ele escuta e corresponde ao apelo primordial da linguagem.

Associa-se à beleza do pensamento dizente uma outra dimensào fundamental para o sentido de conhecimento que a poesia propicia: a dimensão musical. Poesia originalmente é canto. E é enquanto canto que ela tem força poética. Um canto que só se explica - como a poesia - pelo próprio cantar; um canto que não se compreende, não se representa, mas tem um sentido contido em si que precisa ser apreendido na própria atividade de cantar. Tal canto possui um valor cognoscitivo, un sentido que acontece através da conjugação entre o som da palavra e o silêncio, através do agenciamento entre as sonoridades, através do jogo de ritmos e de sucessivas harmonias e desarmonias. O canto também pertence a esse conjunto de saberes da poesia que nos fazem crer que ela nào é puro delírio, devaneio, exercício de imaginação e libertação do esforço mental lógico-racional - um provável bomo demens respondendo ao bomo sapiens - , mas, ao contrário, que ela é uma forma de conhecimento e que existe na linguagem poética uma razâo-poesia a ser movimentada, colocada em ação na apreensão da realidade. Uma razào-poesia presente em toda forma de linguagem, em todo ato de comunicação que precisa ter seu lugar no pensamento comunicacional porque ela tem o grande poder de não só apreender, mas de criar, construir realidades.

A poesia anplia o real porque constrói realidades. Ela não só abarca todo o real em sua forma de expressào, como também é criadora do real. Esta afirmação pode ser taxada de ingènua e idealista. Como se fosse uma resposta fácil à necessidade de sonhar com um lugar na atividade humana que concedesse ao homem o poder criador e esse lugar fosse naturalmente situado pelos sonhadores na poesia por ela ser linguagem criativa. Pensamos que interpretar de tal forma a afirmaçào é apreender o mundo de maneira fragmentar, dando ao homem apenas seu papel de cientista e filósofo, e não também o de artista e poeta. Nossa afirmaçào não é apenas a busca de realização de 
um sonho, trata-se da observação de uma realidade que quer devolver ao homem a sua unidade. Uma unidade do homem que é múltipla e pode sim ser dividida, mas somente na medida em que ela é, acima de tudo, unidade. Sendo assim, reiteramos: a poesia não é apenas linguagem criativa que atende à necessidade de expressão do ser humano, ela é criadora de realidades. O real é manifestação física, mas é também latência, é dado visível mas é também dado invisível, é universo conhecido mas é também mistério, é relação lógica entre as coisas, mas é também paradoxo inexplicável, desconhecido, infinitude.

Nesse sentido, na medida em que a palavra é o instrumento mais imediato e propício ao homem para traduzir o real e se comunicar, ela também é o elemento que lhe permite expressar o que é quase impossivel expressar: o sentimento do mundo, o caráter angustiante de seus paradoxos e de sua infinitude. Tem-se então um desconhecido tornado conhecido, uma realidade desvelada na musicalidade da palavra-imagem.

Se poesia é contemplação do mundo, sensibilidade, imagem, som, ela contempla mundos por ela criados e, sendo assim, vai além da contemplação e se torna experiência, vida, sofrimento, gozo, relato. Suas leis são suficientemente livres e abarcadoras para que ela possa propiciar uma proximidade cada vez mais intensa com as leis misteriosas das conexões ilimitadas entre o homem e o Aberto, designando ao mesmo tempo a experiência com os elementos do conjunto das coisas da conexão e aquilo que, de certa forma, todo homem já é.

É por isso que, enquanto criadora de realidades, a poesia é participante ativa do princípio da comunicação que denominamos de principio com, animador e movimentador do existir, na medida em que ela possui e propicia a conexão ou, simplesmente, possui uma conexão aberta com todas as coisas. Sendo síntese ou unidade de conhecimento que reúne em si palavra, imagem e som, ela funda, desperta e acompanha, criando presenças que acompanham o homem. Isso não é mais uma imagem poética que criamos como um encantamento para a nossa realidade. É uma imagem-pensamento sustentada na noção de "Acompanhar" presente também nas obras de alguns poetaspensadores como Antonio Porchia ${ }^{8}$, René Char e Roberto Juarroz.

8 Laura Cerrato recorda que, no momento da despedida de uma visita na casa do poeta, vinha sempre junto a expressão: "acompanhem-se". Juarroz diz que a poesia cria presenças que nos acompanham. ' $\Lambda$ poesia cria não soluções, fórmulas ou receitas fáceis para a vida, mas companhia para a vida' (apud BOIDO, 1980,27). 
Enquanto Char cria os Transparentes, personagens reais resignificados pela imaginação do poeta e diz deles se acompanhar, Juarroz diz:

O que a poesia busca não é o confortável recurso de uma resposta, mas algo muito mais grave $c$ mais importante para o homem, que é, diante da impossibilidade de respostas, criar presenças que o acompanhem. $\Lambda$ poesia cria, não soluçōes, não fórmulas, nem receitas fáceis para a vida, mas companhia para a vida. (apud BOIDO, 1980, 47)

Não queremos apenas aqui pensar a poesia na comunicação como o fizeram com a arte e a literatura os expoentes do Cultural Sirties e seus seguidores ou como vêm fazendo alguns grupos de pesquisa em Semiótica; queremos pensar poeticamente a comunicação como grande operador cognitivo e prático que determina os limites do conhecimento. A poesia se apresenta, portanto, para nós, como uma abertura epistemológica para o pensamento comunicacional que traz possibilidades metodológicas e teóricas ainda não exploradas. Em termos metodológicos, o pensamento poético é um convite a seguir as vias da cognição sensorial e conceitual possibilitada pela palavra na poesia. Sendo assim, os caminhos do pensar poético tanto podem ser os da harmonia, da beleza e da serenidade como também, por serem caminhos do inexplorado, podem oferecer o risco de se perder ou de não chegar a lugar nenhum. Nesse sentido, são caminhos artiscados.

lsso se apresenta como um desafio e um questionamento epistemológico que, por pouco, não nos paralisa ante o perigo que corremos. O perigo está justamente em propor tal possibilidade. Ao dizermos que entendemos a comunicação - enquanto logos e teclmé que opera a cognição e a ação do conhecer e do agir, e aliar a isso a unidade palavra-imagem-som sintetizadas na poesia, estamos levando a Teoria da Comunicação para horizontes ainda pouco explorados. Aqui, já não é o que a epistemologia da comunicação apreende das teorias e dos paradigmas presentes em outros campos do saber, mas o que os outros campos do saber têm a apreender de uma epistemologia da comunicação que avança sobre os seus próprios limites: o de perguntar à comunicação pela comunicação; o de que inquirir a comunicação sobre os seus fundamentos e essencias, correndo o risco de nada encontrar. 


\section{Considerações finais}

Por que então não atribuir à poesia o seu lugar dentro do pensamento sobre a comunicação? O que impede que, após a longa história das diversas rupturas e do profundo distanciamento entre o modo do conhecimento lógico-racional-científico e o modo poético da apreensão da realidade, iniciemos agora o caminho de volta que religará os saberes desconexos da prosa e da poesia?

A poesia tem sempre algo a dizer. Talvez por isso ela seja simples e clara, mesmo quando é enigmática à primeira vista. Ter algo a dizer pode parecer uma condição necessária a toda produção de linguagem, porém nem sempre o é. Há quem fale por necessidade de aparecer, há quem escreva para repetir o que já foi dito, há quem publique por pura vaidade e todos são repetidores do já dito. Algumas teorias pragmáticas até colocam certos enunciados como performáticos, adiantando que dizer é fazer e analisam assim, à luz do performático, toda a comunicação. Afirmamos com segurança que a poesia tem algo a dizer e o diz com palavras que recebem a beleza do pensamento. A beleza do pensamento se afirma na poesia porque ela é a única maneira de recorrer às formas não desgastadas e vulgarizadas da língua. A poesia tem a virtude de ser livre. Talvez por isso mesmo ela seja tão difícil ao homem acostumado com a rigidez das normas lingüísticas que ele vai adquirindo ao longo da vida. O que importa na poesia é que, com toda sua liberdade, pode-se dizer que ela é a esfera sagrada da língua, aquela capaz de dar vida à linguagem, sendo que ela é a própria linguagem indo em direção à verdade.

Dizer que a poesia recebe a beleza do pensamento e que ela é a única maneira de recorrer às formas não desgastadas e vulgarizadas da língua é colocá-la no centro da produção do pensamento sobre a linguagem entre os homens e sobre a comunicação; é apresentá-la como um caminho a ser percorrido na busca de um entendimento cada vez mais apurado de como o homem se relaciona com o mundo e a natureza através da linguagem. E não será esse um dos questionamentos essenciais do pensamento comunicacional? De que maneira o homem se situa na linguagem? Pergunta que se desdobra em outras tantas, como: a linguagem é forma de expressão do ser humano ou é o ser humano um elo ativo entre a essência das coisas e a humanidade do homem? Se for assim, de onde advém a linguagem? E o que ela representa para ele? Um instrumento? Um meio de expressão? 
Um elo entre o ser humano e a humanidade? Entre o ser humano e a sua essência? Entre o ser humano e as divindades?

Formular tais perguntas exige um pensamento sobre o homem e a sua linguagem que vai além das dimensões horizontais da lingüistica, mesmo com todas as suas conjugações com as outras ciências humanas - sociolingüistica, psicolingüistica, neurolingüistica - mesmo com seus diversos desdobramentos em domínios específicos filologia, etimologia, fonologia, gramatologia, lexicologia, semiologia, etc.; exige um pensamento que não teme conjugar a horizontalidade dos saberes da lingüistica e das ciências humanas com a verticalidade dos saberes poéticos, mesmo que tal conjugação só possa ser feita numa abordagem filosófica e não rigorosamente cientifica; um pensamento que ousa fazer perguntas ingênuas e repondê-las através do desenvolvimento filosófico da poesia. 


\section{Referências}

BOIDO, G. Poesia y creación: Conversaciones con Roberto Juarroz. Buenos Aires: ed. Carlos Lohlé. 1980.

BOSI, A. Ser e tempo da poesia. São Paulo: Companhia das Letras, 2000.

CASTRO, G.e DRAVET, F. Sob o cén da cultura. Brasilia: Thesaurus/Casa das Musas, 2004.

CASTRO, G. e GALENO, A. Jornalismo e literatura: a sedução da palavra. São Paulo: Escrituras, 2002.

CHAR, R. Euvres Complettes. Paris: Gallimard, 1995.

HEIDEGGER, M. Caminhos de floresta. Lisboa: Fundação Calouste Gulbenkian, 1998 (ed. or. 1959a). or. $1959 b)$. - Serenidade. Lisboa: Instituto Piaget, 2000 (ed.

HERÁCLITO. Fragmentos contextualizados. Trad. Alexandre Costa. São Paulo: Difel. 2002.

HÖLDERLIN, F. Poemas. Lisboa: Relógio d'água, 1991.

JUARROZ, R. Poesia y creación. Buenos Aires: Carlos Lohlé, 1980. .Decimocuarta poesía vertical. Buenos Aires: Emecé, 1997.

MORIN, E. Amorpoesia sabedoria. Trad. Edgard de Assis Carvalho. Rio de Janeiro: Bertrand Brasil, 4a. ed. 2002.

NIETSZCHE, F. O Nascimento da tragédia ou belenismo e pesimismo. São Paulo: Cia das Letras, 2007.

NOVALIS. Pólen. São Paulo: Iluminuras, 2001.

PAZ, O. El arco y la lira. México: Fondo de Cultura Económica, $3^{\circ}$ ed. $14^{\circ}$ Reimpressão. 2003.

PLATÃO. A República. Trad. Jacó Ginzburg. São Paulo: perspectiva, 2006.

PORCHIA, A. Voces reunidas. Valencia: Pré-Textos, 2006.

RILKE, M. R. Elegias de Duíno. São Paulo: Globo, 2001. 